\title{
Review Article \\ Microbial Inoculants and Their Impact on Soil Microbial Communities: A Review
}

\author{
Darine Trabelsi and Ridha Mhamdi \\ Laboratory of Legumes, Centre of Biotechnology of Borj-Cédria, P.O. Box 901, 2050 Hammam-Lif, Tunisia \\ Correspondence should be addressed to Ridha Mhamdi; ridha.mhamdi@cbbc.rnrt.tn
}

Received 10 April 2013; Revised 7 June 2013; Accepted 25 June 2013

Academic Editor: Ameur Cherif

Copyright (C) 2013 D. Trabelsi and R. Mhamdi. This is an open access article distributed under the Creative Commons Attribution License, which permits unrestricted use, distribution, and reproduction in any medium, provided the original work is properly cited.

\begin{abstract}
The knowledge of the survival of inoculated fungal and bacterial strains in field and the effects of their release on the indigenous microbial communities has been of great interest since the practical use of selected natural or genetically modified microorganisms has been developed. Soil inoculation or seed bacterization may lead to changes in the structure of the indigenous microbial communities, which is important with regard to the safety of introduction of microbes into the environment. Many reports indicate that application of microbial inoculants can influence, at least temporarily, the resident microbial communities. However, the major concern remains regarding how the impact on taxonomic groups can be related to effects on functional capabilities of the soil microbial communities. These changes could be the result of direct effects resulting from trophic competitions and antagonistic/synergic interactions with the resident microbial populations, or indirect effects mediated by enhanced root growth and exudation. Combination of inoculants will not necessarily produce an additive or synergic effect, but rather a competitive process. The extent of the inoculation impact on the subsequent crops in relation to the buffering capacity of the plant-soil-biota is still not well documented and should be the focus of future research.
\end{abstract}

\section{Introduction}

The application of inoculants is seen as being very attractive since it would substantially reduce the use of chemical fertilizers and pesticides, and there are now an increasing number of inoculants being commercialized for various crops [1]. Microorganisms play an important role in agricultural systems, particularly plant growth-promoting microorganisms (PGPMs). Plant growth benefits may be attributed mainly to three mechanisms as follow. (i) PGPMs acting as biofertilizers (such as nitrogen-fixing bacteria and phosphate-solubilizing bacteria) assist plant nutrient uptake by providing fixed nitrogen or other nutrients [2]. (ii) Phytostimulators (microbes expressing phytohormones such as Azospirillum) can directly promote the growth of plants, usually by producing plant hormones $[3,4]$. (iii) Biological control agents (such as Trichoderma, Pseudomonas, and Bacillus) protect plants against phytopathogenic organisms [5-7]. Several reviews have discussed various aspects of growth promotion by PGPMs [810]. However, the potential environmental impacts related to inoculation were always neglected. Since inoculation consists in supplying high densities of viable and efficient microbes for a rapid colonization of the host rhizosphere, it would induce at least a transient perturbation of the equilibrium of soil microbial communities. Changes in microbial composition may be undesirable if important native species are lost, thus affecting subsequent crops. However, a modification in the bacterial community structure caused by inoculation could be buffered by ecosystem resilience, which is driven by the level of diversity and interactions of the plant-soil-biota [11]. The loss of certain bacterial species may however not change the functioning of the system because of the bacterial redundancy, since different bacterial species may carry out the same functions $[11,12]$.

Soil microbial community is complex and dynamic and varies in composition between different compartments and levels, which represents a real challenge in soil ecology. One of the crucial problems to face in this type of studies is the representativeness of the sampling. Number of replicates, sample size, whether sampling is randomized or at regular 
intervals, spatial scaling, and microsite variation remain major concerns. Most researchers used rhizospheric soil, but even in this case it is practically very difficult to define it precisely. However, the side-distance effect on bulk soil would be more reliable to address a more generalized response. Time-course studies would be also necessary to monitor inoculation effect in relation to the buffering capacity of the ecosystem. Nevertheless, the techniques used to investigate soil microbial communities at taxonomic and functional levels are laborious and limit the use of exhaustive samplings. In the culture-dependent methods, the analysis is usually confined to restricted samples, and a biased image is drawn. However, the culture-independent methods do not usually permit unambiguous identification of taxonomic groups [13]. Besides the bias induced by DNA extraction and PCR amplification, the culture-independent methods represent also some inherent limitations (Table 1).

The high-throughput sequencing techniques, even being more informative $[31,32]$, are still not economically affordable for inoculation impact analysis, because of the high number of samples and replicates involved. There is a growing interest in the recent years in genes and transcripts coding for metabolic enzymes. Besides questions addressing redundancy and diversity, more and more attention is given to the abundance of specific DNA and mRNA in the different habitats [33].

\section{The Rhizosphere: The Unrevealed World}

The rhizosphere represents one of the most diverse habitats on the planet and is central to ecosystem functioning. Infinite dynamic interactions between root exudates, microbial activity, genetic exchange, nutrient transformation, and gradient diffusion are most likely the factors shaping this belowground world (for review, please see [34]). Consequently, there is an increasing need to understand its functioning to effectively manage ecosystem and harness its potential benefits. In particular, manipulation of the rhizosphere is now considered as a key mechanism for solving critical issues facing the planet, including agricultural and forest sustainability, improving water quality, mitigation of climate change, and preservation of biodiversity. To face the range of biotic and abiotic stresses, plants interact with different members of the soil microbial community in many ways and in a complex range of trophic cascades [35]. These relations involve positive and negative feedbacks between soil organisms and plants and their chemical environment. Rhizobacteria communicate within species using diffused chemicals. $\mathrm{N}$ acylhomoserine lactones (N-AHLs) are common signals for bacterial communications in various Gram-negative bacteria [36]. Plant-Microbe interactions are generally regulated by quorum sensing (QS) in a population-dependent manner [37]. Crépin et al. [38] showed that the rhizosphere bacterium Rhodococcus erythropolis catabolizes the N-AHLs produced by the pathogenic bacterium Pectobacterium atrosepticum, thus attenuating its virulence, which suggests a tritrophic belowground chemical interaction. Pathogens exploit QS using N-AHLs to form microcolonies (and biofilm) in the rhizosphere to inflict pathogenicity in the host. By contrast, beneficial or nonpathogenic microbes biosynthesize N-AHLs degrading lactonases to disrupt QS by quorum-quenching [39]. The presence of biostimulating molecules or QS-mimics may also establish microbes that degrade N-AHLs in the rhizosphere, thus reducing the virulence of pathogens. Another example shows that root volatiles may serve as foraging cues for parasitic entomopathogenic nematodes [40], and, then, poorly available organic phosphorus could be made available through the grazing by nematodes of phytaseproducing bacteria [41]. There may be also a synergistic effect of root volatiles and $\mathrm{CO}_{2}$ as attractants for nematodes [42]. Kawasaki et al. [43] showed that some legumes respond to certain contaminants in a systemic manner by utilizing rootcolonizing microorganisms to protect themselves, and they may actively stimulate such microorganisms in the rhizosphere by manipulation of exudates flux and composition. Surfactant-active compounds in the root exudates increase the solubility of the contaminant and make it more bioavailable to root-colonizing microorganisms [44]. The production of plant growth regulators such as auxin, cytokinin, and gibberellin by PGPMs may also interfere on soil microbial communities through an enhanced root growth and an increased exudation rate [45], without excluding the possibility of a direct effect on the microbial equilibrium leading to the selection of beneficial populations. These few examples illustrate the complexity of the rhizospheric interactions and prove that our knowledge about the plant-soil-biota is just beginning.

\section{Inoculation Impact Analysis}

Different soil microorganisms had been extensively used as inoculants, including rhizobia, Azospirillum, mycorrhizal fungi, and biocontrol agents. The most significant studies reporting the effect of these inoculants on soil microbial communities are summarized in Table 2.

3.1. Rhizobia Inoculants. Rhizobia are reported to influence crop growth, yield, and nutrient uptake by different mechanisms. They fix nitrogen, help in promoting free-living nitrogen-fixing bacteria, increase supply of other nutrients, such as phosphorus and iron, produce plant hormones, enhance other beneficial bacteria or fungi, control bacterial and fungal diseases, and help in controlling insect pests [8, $10]$.

Field release of a Rhizobium etli strain containing genes encoding trifolitoxin (an antibiotic peptide active against members of a specific group of $\alpha$-proteobacteria that enhances the ability to compete trifolitoxin-sensitive strains) strongly reduced the diversity of trifolitoxin-sensitive members of $\alpha$-proteobacteria in bean rhizosphere as shown by ribosomal intergenic spacer analysis (RISA), with little apparent effect on most microbes [48]. Using a cultivationdependent approach and a cultivation-independent PCR-single-strand conformation polymorphism (SSCP), Schwieger and Tebbe [14] showed that field release of Sinorhizobium meliloti strain L33 affected bacterial diversity in the rhizosphere of alfalfa by reducing the number 


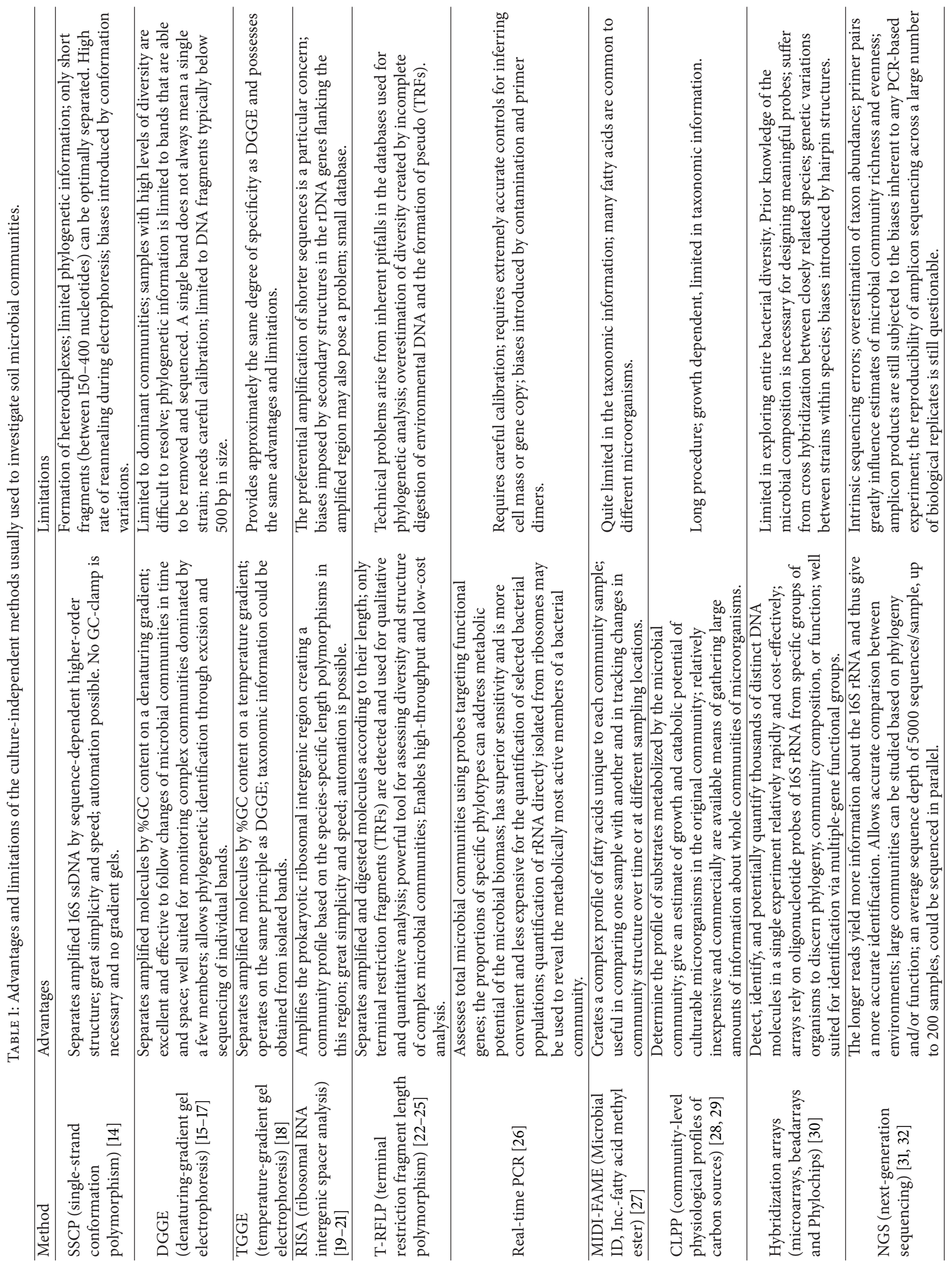


TABLE 2: The most significant studies addressing the impact of inoculation on soil microbial communities.

\begin{tabular}{|c|c|c|c|c|}
\hline Inoculant type & Species & Techniques & Major results & \\
\hline \multirow{5}{*}{ Rhizobia } & S. meliloti L33 & SSCP & $\begin{array}{l}\text { The bacterial diversity in the rhizosphere of Medicago sativa was qualitatively } \\
\text { and quantitatively affected. While the number of members of } \gamma \text {-proteobacteria } \\
\text { decreased, the number of members of } \alpha \text {-proteobacteria increased. }\end{array}$ & {$[14]$} \\
\hline & $\begin{array}{l}\text { Cocktail of Ensifer } \\
\text { strains }\end{array}$ & DGGE & $\begin{array}{l}\text { Field inoculation showed a significant increase of total bacterial diversity due } \\
\text { to seasonal changes, but no effect of rhizobial inoculation was observed. } \\
\text { DGGE offered little information about bacterial communities. }\end{array}$ & {$[17]$} \\
\hline & $\begin{array}{l}\text { S. meliloti } \\
\text { M401/M403 }\end{array}$ & TGGE & $\begin{array}{l}\text { The persistence of certain } \gamma \text {-proteobacterial populations in the rhizosphere of } \\
\text { alfalfa could be affected. TGGE proved to be better for identifying specific } \\
\text { M403-dependent changes. }\end{array}$ & {$[18]$} \\
\hline & $\begin{array}{l}\text { R. gallicum } 8 \mathrm{a} 3 \\
\text { E. meliloti } 4 \mathrm{H} 41\end{array}$ & T-RFLP & $\begin{array}{l}\text { Field inoculation showed significant effects on bacterial structure and } \\
\text { diversity in the bulk soil of common bean. Both } \alpha \text { - and } \gamma \text {-proteobacteria } \\
\text { together with Firmicutes and Actinobacteria were enhanced, including } \\
\text { beneficial bacterial communities with PGPM potentialities. Dual inoculation } \\
\text { was less effective than simple inoculation and induced distinct effects. }\end{array}$ & {$[22,23]$} \\
\hline & S. meliloti S26/OS6 & qPCR & $\begin{array}{l}\text { The bacterial genes involved in nitrogen turnover were affected by } \\
\text { inoculation. The effectiveness of inoculation was related to the abundance of } \\
\text { nif } \mathrm{H} \text { genes in the late flowering phase. A higher number of amoA copies were } \\
\text { observed during flowering. }\end{array}$ & {$[26]$} \\
\hline \multirow{3}{*}{ Azospirillum } & A. brasilense Cd/Sp245 & $\begin{array}{l}\text { DGGE } \\
\text { RISA }\end{array}$ & $\begin{array}{l}\text { Field inoculation showed no prominent effects on bacterial communities of } \\
\text { maize in two different soils and in different growth systems. }\end{array}$ & {$[21]$} \\
\hline & A. lipoferum CRT1 & RISA & $\begin{array}{l}\text { Field inoculation of maize increased the intersample variability of the } \\
\text { bacterial community between individual plants and sampling times without } \\
\text { modifying the total number of root bacteria. }\end{array}$ & {$[19,20]$} \\
\hline & $\begin{array}{l}\text { A. brasilense } \\
40 \mathrm{M} / 42 \mathrm{M}\end{array}$ & CLPPs & $\begin{array}{l}\text { Inoculation changed the community-level physiological profiles of the } \\
\text { cultivable microbial communities associated with rice roots. }\end{array}$ & [29] \\
\hline \multirow[t]{2}{*}{$\mathrm{AMF}$} & G. intraradices & DGGE & $\begin{array}{l}\text { Inoculation affected the composition of the rhizosphere bacterial community } \\
\text { of pea. Four to five specific bands were suppressed. Before flowering, the AMF } \\
\text { decreased rhizosphere respiration and number of protozoa, but it did not } \\
\text { affect bacterial number. During flowering and pod formation, the AMF } \\
\text { stimulated rhizosphere respiration and the negative effect on protozoa } \\
\text { decreased. }\end{array}$ & {$[46]$} \\
\hline & $\begin{array}{l}\text { G. mosseae } \\
\text { G. intraradices }\end{array}$ & DGGE & $\begin{array}{l}\text { Inoculation significantly modified the rhizosphere bacterial composition of } \\
\text { tomato. The two AMFs had had similar bacterial communities; however, } \\
\text { specific species-dependent effects were observed. }\end{array}$ & {$[47]$} \\
\hline \multirow{2}{*}{$\begin{array}{l}\text { Biocontrol } \\
\text { agents }\end{array}$} & P. fluorescens 2P24 & $\begin{array}{l}\text { T-RFLP } \\
\text { DGGE }\end{array}$ & $\begin{array}{l}\text { Inoculation induced a transient effect on fungal community in the } \\
\text { rhizosphere of cucumber suggesting that this biocontrol agent has a limited } \\
\text { validity. DGGE and T-RFLP showed similar results. }\end{array}$ & {$[25]$} \\
\hline & $\begin{array}{l}\text { P. chlororaphis IDV1 } \\
\text { P. putida RA2 }\end{array}$ & FAME & $\begin{array}{l}\text { Inoculation induced shifts in fatty acid methyl ester profiles of cultivable } \\
\text { bacteria fractions, as well as total microbial communities in the rhizosphere of } \\
\text { maize. The rhizosphere composition shifted from a Gram-positive-dominated } \\
\text { community to more Gram-negative populations. }\end{array}$ & [27] \\
\hline \multirow{3}{*}{ Coinoculation } & $\begin{array}{l}\text { Pseudomonas spp. } \\
\text { AMF }\end{array}$ & DGGE & $\begin{array}{l}\text { Inoculation induced a significant modification in the bacterial community } \\
\text { structure. The type of PGPM consortium had more impact on the bacterial } \\
\text { community structure than the presence of AMF. A synergistic effect of } \\
\text { coinoculation was observed. }\end{array}$ & {$[15]$} \\
\hline & $\begin{array}{l}\text { B. subtilis } 101 \\
\text { A. brasilense } \mathrm{Sp} 245\end{array}$ & DGGE & $\begin{array}{l}\text { Inoculation with the biocontrol agent did not show significant effects on } \\
\text { fungal ( } 18 \mathrm{~S} \text { rRNA) and bacterial (16S rRNA) communities in the rhizosphere } \\
\text { of tomato. Combination of the two rhizobacteria had no synergistic or } \\
\text { comparable effects on plant biomass, with respect to their single applications. }\end{array}$ & {$[16]$} \\
\hline & $\begin{array}{l}\text { A. brasilense } \\
\text { P. fluorescens }\end{array}$ & $\begin{array}{l}\text { T-RFLP } \\
\text { CLPPs }\end{array}$ & $\begin{array}{l}\text { Inoculation did not show significant impact on cultivable communities and } \\
\text { nif } \mathrm{H} \text { T-RFLP-patterns of diazotrophic bacteria associated with rice roots. A } \\
\text { synergistic effect of coinoculation was found. }\end{array}$ & {$[24]$} \\
\hline
\end{tabular}


of $\gamma$-proteobacteria and increasing the number of $\alpha$ proteobacteria. The shift was interpreted as a replacement of more general bacteria (Acinetobacter calcoaceticus and Pseudomonas sp.) by specialists (rhizobia). The indigenous microbial populations in the rhizosphere of alfalfa inoculated with S. meliloti strain M403 (a strain with enhanced competitiveness for nodule occupancy constructed by introducing an extra copy of a modified proline dehydrogenase gene) or strain M401 (a control strain carrying the same plasmid without the modified gene) were evaluated by comparing restriction fragment length polymorphism (RFLP) and temperature-gradient gel electrophoresis fingerprints (TGGE) of $16 \mathrm{~S}$ rDNA genes directly amplified from soil DNA [18]. Seasonal changes were observed in RFLP patterns only when primers specific for $\beta$ - and/or $\gamma$-proteobacteria were used. RFLP analysis showed that inoculation permitted certain $\gamma$-proteobacterial populations to be maintained longer and persist in the rhizosphere of alfalfa. Seasonal changes were also detected by TGGE performed with $\alpha$-proteobacterial primers but not with $\beta$-proteobacterial primers [18]. Therefore, in the TGGE patterns appeared two bands specifically correlated to inoculation with M403, showing sequence similarity, respectively, to Rahnella aquatilis and Kluyvera georgiana. The seasonal fluctuations induced by environment and alfalfa plants showed much stronger influence on the microbial community than the inoculation-dependent effects.

The quantification of bacterial genes encoding the nitrogenase reductase $(n i f \mathrm{H})$, ammonia monooxygenase (amoA), and nitrite reductase (nirK and nirS), as well as archaeal $a m o \mathrm{~A}$ genes within the nitrogen cycle, was performed in alfalfa rhizosphere inoculated with S. meliloti strains S26 and OS6 [26]. At the late flowering phase, a clear correlation was demonstrated between effectiveness of inoculation, as evaluated by nitrogen and carbon contents, and the abundance of nif $\mathrm{H}$ genes. Moreover, the number of archaeal amoA copies increased upon the more effective strain inoculation.

The effects of growth stage, intercropping, and rhizobial inoculation on diversity of soybean endophytic bacteria were demonstrated by the cluster analysis of terminal restriction fragments and the redundancy analysis [49]. The relative abundance in roots was enhanced for Bradyrhizobium liaoningense and decreased for Sinorhizobium americanum, demonstrating that the endophytic Sinorhizobium might be suppressed by competition from the introduced strain. The difference in abundance of endophytic Sinorhizobium, Bradyrhizobium, and Rhizobium in the soybean roots could be correlated to the nodulation autoregulation system of legumes, which is capable of sensing and responding to the presence of inefficient rhizobia by applying sanctions to inactive strains via active control of the permeability of root cortical cells to oxygen, thus limiting the growth of inefficient nodules [20]. A $517 \mathrm{bp} \mathrm{TRF}$ assigned to Comamonadaceae and Burkholderiales showed a higher abundance in inoculated soybeans [49]. The abundance of rhizosphere Comamonadaceae bacteria has been previously reported to be associated with mycorrhization [50], and, on the other hand, the latter could be stimulated by the rhizobial inoculation of soybean [51].
In our lab, the effect of on-field inoculation of Phaseolus vulgaris with two local rhizobial strains was addressed by exploring community structure and diversity using similarity analysis of T-RFLP profiles. Effects on bacterial community structure and diversity were clearly observed in the bulk soil in the neighborhood of $25 \mathrm{~cm}$ of the roots [22]. Both $\alpha$ - and $\gamma$ proteobacteria together with Firmicutes and Actinobacteria were enhanced by inoculation. The mono- and dual inoculation with Rhizobium gallicum strain $8 \mathrm{a} 3$ and Ensifer meliloti strain $4 \mathrm{H} 41$ induced the proliferation of bacterial communities that had been frequently reported as PGPMs, like Rahnella, Bacillus, Azospirillum, Mesorhizobium, Pseudomonas, Streptomyces, and Sinorhizobium, among others [23]. The extent of these changes was also seen in the next rotation crop as indicated by the $32 \%$ increase observed in potato yield, and also by the $56 \%$ decrease in potato wireworm infestation [23]. The number of TRFs is significantly higher in the inoculated treatments than that in the nitrogen-fertilized treatment during flowering and harvesting stages. Similarly, there was a clear trend of increase in intersample heterogeneity of bacterial communities in the inoculated treatment up to the harvesting stage. These data suggest that the perturbation of the community due to inoculation with a rhizobial strain is higher than that due to chemical fertilization and that the evolution of the community in response to inoculants is someway more stochastic, suggesting that the introduction of exogenous bacteria in a community is likely to produce more long-term unpredictable effects than organic nitrogen supply.

3.2. Azospirillum Inoculants. The agronomic benefits of Azospirillum are well documented [52, 53]. Several modes of action are implicated [45], especially the synthesis of phytohormones such as indole-3-acetic acid $[3,54]$. Since Azospirillum inoculation can have a great effect on root development and exudation $[53,55]$, it is likely that the use of these phytostimulatory PGPMs will also modify the resident microbial community structure of the rhizosphere. Using the automated ribosomal intergenic spacer analysis (ARISA), inoculation of maize with Azospirillum lipoferum CRT1 was seen to increase the variability in the genetic diversity of the rhizobacterial communities between individual field-grown maize plants and between sampling times without modifying the total number of root bacteria $[19,20]$. In other studies, the plant growth development was improved with Azospirillum brasilense Sp245 by production of auxins, cytokinins, and gibberellins [56]. Root physiology and architecture changed, and root surface area increased through production of more root hairs, leading to an increase in mineral uptake. However, no prominent effects were observed on bacterial communities of maize grown in two different soils and in different growth systems as indicated by DGGE and ARISA [21]. Naiman et al. [28] showed also that inoculation with Azospirillum and Pseudomonas may exert different effects on the number of specific subgroups of cultivable bacteria in the rhizosphere of wheat. Inoculation changed the profiles of carbon source (CS) utilization of the soil microflora at tillering and grainfilling stages. The CS utilization is related on one hand to the number of microorganisms which are able to use each CS as a sole carbon supply. on the other hand, the importance 
of growth is a reflection of the functional potential of the community.

Inoculation with two A. brasilense strains (40M and 42M) isolated from maize roots changed also the community-level physiological profiles (CLPPs) of the cultivable microbial communities associated with rice [29]. Although the average values of absorbance for arginine showed that the microbial communities associated with inoculated and control plants had significant differences in ability to use arginine, a moderate effect on the physiological and genetic characteristics of microbial communities associated with certain rice cultivars was found under field conditions [24]. The nif H T-RFLPpatterns of diazotrophic communities associated with rice roots showed that some of the restriction fragments permitted differentiation of inoculation treatments, such as the $66 \mathrm{bp}$ fragment that could correspond to Methylogaea oryzae which is a methanotrophic bacterium associated with rice [24]. These data suggest that the hormonal effect exercised by Azospirillum improves the efficiency of the nitrogen absorption leading to superior yields of biomass. The overall rhizosphere diversity, mainly of specific functional groups, is most likely influenced by the change in residual nitrogen rather than the direct effect of inoculation. However, the specific mechanisms causing these changes are still not clear and need to be extensively studied.

3.3. Mycorrhizal Fungi Inoculants. Arbuscular mycorrhizal fungi (AMF), grouped into the phylum Glomeromycota [57], have the ability to form mutualistic symbiosis with most land plants and colonize a wider soil volume. They receive carbon from their host, benefiting plant growth through their ability to exploit resources and delivering minerals and water back [58]. AMF affect the soil microorganisms associated with their extraradical mycelium, leading to the formation of a specific zone of soil called the mycorrhizosphere $[59,60]$. In the mycorrhizosphere, the AMF might affect negatively [61], positively [62], or may have no effect [63] on microbial biomass and growth of specific microbial taxa [64]. Many studies have shown that some bacterial species respond to the presence of certain AMF $[59,65]$, suggesting a high degree of specificity between bacteria associated with AMF. Thus, the specific bacteria together with AMF may create more indirect synergism for plant growth [66] including nutrient acquisition [67] and enhancement of root branching [68]. AMF may inhibit pathogen proliferation through the formation of a bacterial community that limits the pathogen invasion [69, 70]. Glomus intraradices has been shown to affect positively the bacterial and saprotrophic fungal biomass in a root-free sand environment [62]. Using DGGE of 16S rRNA amplicons from total DNA extracts of pea rhizosphere, Wamberg et al. [46] showed that DGGE profiles were relatively similar between AMF-inoculated and AMF-uninoculated treatments. However, G. intraradices-inoculated treatments showed suppression of four to five specific bright bands. These types of changes were also studied in the extreme conditions characteristic of mine tailings [71]. Canonical correspondence analysis of DGGE profiles showed that AMF inoculation significantly influenced the development of both fungal and bacterial rhizosphere community structures after two months. It was reported that the changes observed in the mesquite rhizosphere microbial community structure may be either a direct or an indirect effect of the AMF used. One type of direct interaction between the AMF and bacterial populations in the rhizosphere is the stimulation or suppression of one or more susceptible populations [72]. It was shown that the exudates of the extraradical mycelium of $G$. intraradices could significantly inhibit the conidial germination of the plant pathogen Fusarium oxysporum in transformed carrot roots [73]. By contrast, the PGPM Pseudomonas chlororaphis was strongly stimulated. One type of indirect effects of $G$. intraradices is the induction of systemic resistance against the parasitic nematodes Radopholus similis and Pratylenchus coffeae in banana plants [74]. Lioussanne et al. [47] showed that direct root colonization with either $G$. mosseae or G. intraradices significantly modified the DGGE bacterial community structure of tomato rhizosphere. The two AMF species had similar bacterial communities after four weeks. The bacterial taxa associated with the rhizosphere of tomato plants inoculated with G. mosseae were identified as Pseudomonas, Herbaspirillum, and Acidobacterium, while a Bacillus simplex (clone TR03) was found to be affiliated only with G. intraradices. One clone (TR2) that was ambiguously identified as Pseudomonas entomophila, Pseudomonas plecoglossicida, or Pseudomonas putida has been associated with both $G$. intraradices and $G$. mosseae. Taken together, all these works showed that AMF can support modification in microbial community structure within mycorrhizosphere. The identification of key microbial populations that are correlated with improved biomass production will help to understand the role of the microbial community in supporting plant growth, suppressing plant pathogen invasion, and other AMF functional abilities.

3.4. Biocontrol Inoculants. Most of the commercial rhizobacterial products have been marketed for biological control of plant diseases rather than augmenting plant nutrition or minimizing abiotic stress impacts [1]. A number of microorganisms such as Trichoderma harzianum [5, 75], Pseudomonas fluorescens [6], and Bacillus subtilis [7] have demonstrated antagonism against diseases caused by Fusarium spp., Pythium spp., Rhizoctonia spp., Sclerotium spp., and so forth, leading to enhancement in plant growth or yield. It has been established also that application of B. subtilis [75], Pochonia chlamydosporia [76, 77], and P. fluorescens [78-80] can effectively control the diseases caused by nematodes.

Two species of Pseudomonas showing antagonistic activity against the tomato pathogen Ralstonia solanacearum [27] were assessed for their impacts on the rhizosphere microbial community structure of maize. Shifts in fatty acid methyl ester (FAME) profiles of cultivable bacteria fractions, as well as total rhizosphere microbial communities, were determined in answer to inoculation. The introduced $P$. chlororaphis IDV1 and $P$. putida RA2 showed good survival in the maize rhizosphere. However, both inoculants revealed a small growth-reducing effect towards maize, probably due to changes in the indigenous rhizosphere communities. The community structure transitorily shifted following domination of specific slow-growing bacterial classes. 
The cultivable fraction of bacteria was represented by high biomass of Gram-positives (i.e., Bacillus and Arthrobacter) as indicated by the contents of branched FAMEs (especially iso/anteiso 15:0/17:0). During the later growth stage of maize, this group was disturbed by the introduced strains. Actinomycetes, as indicated by fatty acids with a methyl group at carbon 10 of the chain [81], could be supported by young roots of maize, but this effect was inhibited by inoculation [27]. Both P. chlororaphis IDV1 and P. putida RA2 survived at relatively high density after release, suggesting their direct impact on community structure. In addition, the inoculation shift from Gram-positive-dominated community to more Gram-negative populations might be indicative of a progressive change from oligotrophic to more copiotrophic conditions [82], which could be due to the treatment effect (i.e., nutrients released from dead cells) [27].

To assess the impact of intentionally applied microorganisms on several key ecological aspects of the microbial decomposer community in plant litter, wheat straw on pans of soil was inoculated with either the fungus Limonomyces roseipellis or the bacterium $P$. fluorescens strain Pf-5, biocontrol agents for Pyrenophora tritici-repentis [83]. Pseudomonas fluorescens had insignificant effect, but $L$. roseipellis had measurable effects on some aspects of microbial community structure and function. Limonomyces roseipellis altered the frequency distribution of fungal taxa on straw by increasing yeasts and decreasing saprophytic fungi such as Alternaria and Cladosporium. Compared with nontreated straw, respiration under conditions of adequate moisture $(-0.1 \mathrm{MPa})$ was increased by $L$. roseipellis, but it was unaffected at water potential of $-7 \mathrm{MPa}$. The spectrum of sole carbon sources utilized by the straw microflora was slightly altered in Limonomyces-treated straw [83]. This change in metabolic capabilities is attributed to changes in microbial community.

The effects of Douglas fir (Pseudotsuga menziesii) coinoculation with the mycorrhiza helper bacterial strain $P$. fluorescens BBc6R8 and/or the fungal strain Laccaria bicolor $\mathrm{S} 238 \mathrm{~N}$ on the indigenous bacterial and ectomycorrhizal communities were assessed using quantitative and qualitative approaches [84]. The inoculated bacterial strain BBc6R8 was not detected after 4 years in any of the treatments where it was speculated that the lack of bacterial effect on seedling growth was due to the nonpersistence of the inoculated bacteria. When $P$. fluorescens BBc6R8 was introduced at sowing, Frey-Klett et al. [85] showed a positive effect of bacterial inoculation on the Douglas fir-L. bicolor symbiosis despite the bacteria only surviving for up to 19 weeks in the glasshouse and field soil. Heinonsalo et al. [84] suggested that the absence of positive bacterial effect could be due to the too late inoculation of bacteria on already mycorrhized seedlings and that the mycorrhiza helper bacteria promoted the presymbiotic survival of the fungus in the soil. Transient effects on soil microbial communities were found following the inoculation with biocontrol agents, such as P. fluorescens [86], Streptomyces melanosporofaciens [87], and Corynebacterium glutamicumin [88]. In a recent work, the effect of $P$. fluorescens 2P24 on soil fungal community in cucumber rhizosphere was detected with T-RFLP and DGGE [25]. The results showed that inoculation had a transient significant effect on soil fungal community, indicating that the period of validity of the biocontrol agent may be limited. All of these results suggest that inoculation with biocontrol agents breaks the original ecological balance of soil microbial community; however, a progressive recovery is commonly observed following fading of the released strain. The effects on soil microbial communities seem more pronounced and more maintained in case of biofertilizers and phytostimulators having direct effects on plants. It is likely that plants amplify and contribute in maintaining the observed effect. Root colonization is certainly a key step in this process.

\section{Coinoculation versus Monoinoculation}

Most inoculants often rely on application of a single strain which might partially account for the recorded inconsistencies in field. A way to overcome this problem is to include different species or strains of beneficial microbes in the same microbial formulation. Coinoculation would combine different mechanisms without the need for genetic engineering [89], increase plant performance, and enhance the efficacy and reliability of healthy effects on crops [90].

Roesti et al. [15] analyzed the effects of PGPR/AMF inoculations on bacterial community structure of wheat rhizosphere. DGGE analysis showed that inoculants induced a significant modification in the bacterial community structure. However, the type of PGPR consortium had more impact on the bacterial community structure $(28.3 \%$ of the variance) than the presence of AMF (10.6\% of the variance). Even though the PGPR strains used produce the antibiotic 2.4-diacetylphloroglucinol, which is known for its antifungal properties, the AMF growth was not affected, and a synergistic effect of PGPR/AMF coinoculation was observed.

The effect of inoculation of Pinus pinea with Bacillus licheniformis CECT 5106 and Bacillus pumilus CECT 5105 was evaluated [91]. Both Bacillus strains promoted the growth of $P$. pinea seedlings (probably by gibberellin production), but this biological effect was absent when both strains were coinoculated, indicating a competition effect. The phospholipid fatty acids composition was also altered, despite the low levels of inoculants found at the end of the assay [91].

Also, the combination of B. subtilis and A. brasilense did not show synergistic or comparable effects on tomato growth comparing with their single applications. Rather, the mutual presence of these microorganisms, other than reducing plant growth, could cause root-architectural alterations [16]. Our results showed also [23] a reduced efficacy of dual inoculation comparing with single inoculations with two rhizobial strains. TRF composition was more diverse in the case of single inoculations. Some of these differentiating TRFs could be affiliated to the genera known as anaerobic nitrogen-fixing consortia and phytohormone producers (i.e., Clostridium, Bacillus, Stenotrophomonas, and Xanthomonas), which may explain the difference in plant growth. Therefore, combination of inoculants will not necessarily produce an additive or synergic effect, but rather a competitive process, and, hence, growth enhancement could be reduced or eventually disappear. Consequently, the effects on soil microbial communities will be also unpredictable. 


\section{Conclusion}

Microbial inoculation may cause tremendous changes in the number and composition of the taxonomic groups. However, the observed impacts depend largely on the techniques used to address the dynamics of soil microbial communities. Some works showed no effect or a transient effect; however, others evidenced a long-term effect. These changes may influence plant and soil and thereby induce unpredictable feedback reactions. Effects on plant growth and protection are not necessarily resulting from a direct effect of the inoculated strain and may be related to induction or repression of resident microbial populations. There may be also synergistic/antagonistic interactions between target and nontarget effects. These changes could well lead to changes in beneficial soil functions such as nitrogen fixation or N-cycling bacteria. The extent of these changes on soil biology is still not well documented and needs to be further assessed. The major concern remains regarding how the impact on taxonomic groups can be related to effects on functional capabilities of the soil microbial communities. The dynamics of these effects in relation to the host crop, the side-distance effect, the midterm and long-term effects, the crop-rotation effect, and site variation are still not understood and need to be further investigated. Undesirable growing conditions, such as biotic and abiotic stresses, most likely contribute to inconstancy of results and further complicate the problem, but they should be expected as a normal functioning of agriculture. With the evolution of the DNA-sequencing techniques and their accessibility for many working groups, more light will be shed on the complexity of the metabolic potentials of soil microbial communities and their importance to soil ecosystem.

\section{Acknowledgments}

The authors would like to thank the anonymous reviewers for their valuable comments and suggestions to improve this paper.

\section{References}

[1] G. Berg, "Plant-microbe interactions promoting plant growth and health: perspectives for controlled use of microorganisms in agriculture," Applied Microbiology and Biotechnology, vol. 84, no. 1, pp. 11-18, 2009.

[2] I. R. Kennedy and N. Islam, "The current and potential contribution of asymbiotic nitrogen fixation to nitrogen requirements on farms: a review," Australian Journal of Experimental Agriculture, vol. 41, no. 3, pp. 447-457, 2001.

[3] S. Spaepen, J. Vanderleyden, and R. Remans, "Indole-3-acetic acid in microbial and microorganism-plant signaling," FEMS Microbiology Reviews, vol. 31, no. 4, pp. 425-448, 2007.

[4] B. R. Glick, B. Todorovic, J. Czarny, Z. Cheng, J. Duan, and B. McConkey, "Promotion of plant growth by bacterial ACC deaminase," Critical Reviews in Plant Sciences, vol. 26, no. 5-6, pp. 227-242, 2007.

[5] F. A. Mohiddin, M. R. Khan, and S. M. Khan, "Why Trichoderma is considered super hero (super fungus) against the evil parasites?” Plant Pathology Journal, vol. 9, pp. 1-11, 2010.
[6] S. Peighami-Ashnaei, A. Sharifi-Tehrani, M. Ahmadzadeh, and K. Behboudi, "Interaction of different media on production and biocontrol efficacy of Pseudomonas fluorescens P-35 and Bacillus subtilis B-3 against grey mould of apple," Journal of Plant Pathology, vol. 91, no. 1, pp. 65-70, 2009.

[7] S. Dawar, S. Wahab, M. Tariq, and M. J. Zaki, "Application of Bacillus species in the control of root rot diseases of crop plants," Archives of Phytopathology and Plant Protection, vol. 43, no. 4, pp. 412-418, 2010.

[8] H. Antoun and D. Prevost, "Ecology of plant growth promoting rhizobacteria," in PGPR: Biocontrol and Biofertilization, Z. A. Siddiqui, Ed., pp. 1-38, 2005.

[9] X. Zhuang, J. Chen, H. Shim, and Z. Bai, "New advances in plant growth-promoting rhizobacteria for bioremediation," Environment International, vol. 33, no. 3, pp. 406-413, 2007.

[10] B. S. Saharan and V. Nehra, "Plant growth promoting rhizobacteria: a critical review," Life Sciences and Medicine Research, vol. 21, pp. 1-30, 2011.

[11] A. C. Kennedy, "Bacterial diversity in agroecosystems," Agriculture, Ecosystems and Environment, vol. 74, no. 1-3, pp. 65-76, 1999.

[12] P. Nannipieri, J. Ascher, M. T. Ceccherini, L. Landi, G. Pietramellara, and G. Renella, "Microbial diversity and soil functions," European Journal of Soil Science, vol. 54, no. 4, pp. 655-670, 2003.

[13] P. R. Hirsch, T. H. Mauchline, and I. M. Clark, "Cultureindependent molecular techniques for soil microbial ecology," Soil Biology and Biochemistry, vol. 42, no. 6, pp. 878-887, 2010.

[14] F. Schwieger and C. C. Tebbe, "Effect of field inoculation with Sinorhizobium meliloti L33 on the composition of bacterial communities in rhizospheres of a target plant (Medicago sativa) and a non-target plant (Chenopodium album)-linking of $16 \mathrm{~S}$ rRNA gene-based single-strand conformation polymorphism community profiles to the diversity of cultivated bacteria," Applied and Environmental Microbiology, vol. 66, no. 8, pp. 3556-3565, 2000.

[15] D. Roesti, R. Gaur, B. N. Johri et al., "Plant growth stage, fertiliser management and bio-inoculation of arbuscular mycorrhizal fungi and plant growth promoting rhizobacteria affect the rhizobacterial community structure in rain-fed wheat fields," Soil Biology and Biochemistry, vol. 38, no. 5, pp. 1111-1120, 2006.

[16] C. Felici, L. Vettori, E. Giraldi et al., "Single and co-inoculation of Bacillus subtilis and Azospirillum brasilense on Lycopersicon esculentum: effects on plant growth and rhizosphere microbial community," Applied Soil Ecology, vol. 40, no. 2, pp. 260-270, 2008.

[17] L. Herrmann, K. Sanon, A. M. Zoubeirou et al., "Seasonal changes of bacterial communities in the rhizosphere of Acacia senegal mature trees inoculated with Ensifer strains in Burkina Faso and Niger," Agriculture, Ecosystems and Environment, vol. 157, pp. 47-53, 2012.

[18] P. Van Dillewijn, P. J. Villadas, and N. Toro, "Effect of a Sinorhizobium meliloti strain with a modified putA gene on the rhizosphere microbial community of alfalfa," Applied and Environmental Microbiology, vol. 68, no. 9, pp. 4201-4208, 2002.

[19] E. Baudoin, S. Nazaret, C. Mougel, L. Ranjard, and Y. MoënneLoccoz, "Impact of inoculationwith the phytostimulatory PGPR Azospirillum lipoferum CRT1 on the genetic structure of the rhizobacterial community of field-grown maize," Soil Biology and Biochemistry, vol. 41, no. 2, pp. 409-413, 2009. 
[20] O. Schumpp and W. J. Deakin, "How inefficient rhizobia prolong their existence within nodules," Trends in Plant Science, vol. 15, no. 4, pp. 189-195, 2010.

[21] A. Lerner, Y. Herschkovitz, E. Baudoin et al., "Effect of Azospirillum brasilense inoculation on rhizobacterial communities analyzed by denaturing gradient gel electrophoresis and automated ribosomal intergenic spacer analysis," Soil Biology and Biochemistry, vol. 38, no. 6, pp. 1212-1218, 2006.

[22] D. Trabelsi, H. Ben Ammar, A. Mengoni, and R. Mhamdi, "Appraisal of the crop-rotation effect of rhizobial inoculation on potato cropping systems in relation to soil bacterial communities," Soil Biology and Biochemistry, vol. 54, pp. 1-6, 2012.

[23] D. Trabelsi, A. Mengoni, H. Ben Ammar, and R. Mhamdi, "Effect of on-field inoculation of Phaseolus vulgaris with rhizobia on soil bacterial communities," FEMS Microbiology Ecology, vol. 77, no. 1, pp. 211-222, 2011.

[24] I. E. García de Salamone, J. M. Funes, L. P. Di Salvo et al., "Inoculation of paddy rice with Azospirillum brasilense and Pseudomonas fluorescens: impact of plant genotypes on rhizosphere microbial communities and field crop production," Applied Soil Ecology, vol. 61, pp. 196-204, 2012.

[25] G. Gao, D. Yin, S. Chen et al., "Effect of biocontrol agent Pseudomonas fluorescens $2 \mathrm{P} 24$ on soil fungal community in cucumber rhizosphere using T-RFLP and DGGE," PLoS ONE, vol. 7, no. 2, Article ID e31806, 2012.

[26] K. H. Babić, K. Schauss, B. Hai et al., "Influence of different Sinorhizobium meliloti inocula on abundance of genes involved in nitrogen transformations in the rhizosphere of alfalfa (Medicago sativa L.)," Environmental Microbiology, vol. 10, no. 11, pp. 2922-2930, 2008.

[27] J. Kozdrój, J. T. Trevors, and J. D. Van Elsas, "Influence of introduced potential biocontrol agents on maize seedling growth and bacterial community structure in the rhizosphere," Soil Biology and Biochemistry, vol. 36, no. 11, pp. 1775-1784, 2004.

[28] A. D. Naiman, A. Latrónico, and I. E. García de Salamone, "Inoculation of wheat with Azospirillum brasilense and Pseudomonas fluorescens: impact on the production and culturable rhizosphere microflora," European Journal of Soil Biology, vol. 45, no. 1, pp. 44-51, 2009.

[29] I. E. G. de Salamone, L. P. Di Salvo, J. S. E. Ortega, P. M. F. B. Sorte, S. Urquiaga, and K. R. S. Teixeira, "Field response of rice paddy crop to Azospirillum inoculation: physiology of rhizosphere bacterial communities and the genetic diversity of endophytic bacteria in different parts of the plants," Plant and Soil, vol. 336, no. 1, pp. 351-362, 2010.

[30] K. Schreiner, A. Hagn, M. Kyselková et al., "Comparison of barley succession and take-all disease as environmental factors shaping the rhizobacterial community during take-all decline," Applied and Environmental Microbiology, vol. 76, no. 14, pp. 4703-4712, 2010.

[31] J. G. Caporaso, C. L. Lauber, W. A. Walters et al., "Global patterns of $16 \mathrm{~S}$ rRNA diversity at a depth of millions of sequences per sample," Proceedings of the National Academy of Sciences of the United States of America, vol. 108, no. 1, pp. 4516$4522,2011$.

[32] I. Han, T. K. Lee, J. Han, T. V. Doan, S. B. Kim, and J. Park, "Improved detection of microbial risk of releasing genetically modified bacteria in soil by using massive sequencing and antibiotic resistance selection," Journal of Hazardous Material, vol. 227-228, pp. 172-178, 2012.
[33] G. Rastogi and R. K. Sani, "Molecular techniques to assess microbial community structure, function, and dynamics in the environment," in Microbes and Microbial Technology: Agricultural and Environmental Applications, I. Ahmad, F. Ahmad, and J. Pichtel, Eds., pp. 29-57, 2011.

[34] G. Benckiser and S. S. Bamforth, "Role of pathogens, signal recalcitrance, and organisms shifting for ecosystem recuperation: a review," Agronomy for Sustainable Development, vol. 31, no. 1, pp. 205-215, 2011.

[35] D. L. Jones and P. Hinsinger, "The rhizosphere: complex by design," Plant and Soil, vol. 312, no. 1-2, pp. 1-6, 2008.

[36] S. B. von Bodman, W. D. Bauer, and D. L. Coplin, "Quorum sensing in plant-pathogenic bacteria," Annual Review of Phytopathology, vol. 41, pp. 455-482, 2003.

[37] N. A. Whitehead, A. M. L. Barnard, H. Slater, N. J. L. Simpson, and G. P. C. Salmond, "Quorum-sensing in Gram-negative bacteria," FEMS Microbiology Reviews, vol. 25, no. 4, pp. 365404, 2001.

[38] A. Crépin, C. Barbey, A. Cirou et al., "Biological control of pathogen communication in the rhizosphere: a novel approach applied to potato soft rot due to Pectobacterium atrosepticum," Plant and Soil, vol. 358, no. 1-2, pp. 27-37, 2012.

[39] H. P. Bais, "Shoot the messages not the messengers," Plant and Soil, vol. 358, pp. 7-10, 2012.

[40] T. C. J. Turlings, I. Hiltpold, and S. Rasmann, "The importance of root-produced volatiles as foraging cues for entomopathogenic nematodes," Plant and Soil, vol. 358, pp. 51-60, 2012.

[41] U. Irshad, A. Brauman, C. Villenave, and C. Plassard, "Phosphorus acquisition from phytate depends on efficient bacterial grazing, irrespective of the mycorrhizal status of Pinus pinaster," Plant and Soil, vol. 358, no. 1-2, pp. 155-168, 2012.

[42] J. Jin, C. Tang, R. Armstrong, and P. Sale, "Phosphorus supply enhances the response of legumes to elevated CO2 (FACE) in a phosphorus-deficient vertisol," Plant and Soil, vol. 358, no. 1-2, pp. 91-104, 2012.

[43] A. Kawasaki, E. R. Watson, and M. A. Kertesz, "Indirect effects of polycyclic aromatic hydrocarbon contamination on microbial communities in legume and grass rhizospheres," Plant and Soil, pp. 1-14, 2011.

[44] R. Child, C. D. Miller, Y. Liang et al., "Polycyclic aromatic hydrocarbon-degrading Mycobacterium isolates: their association with plant roots," Applied Microbiology and Biotechnology, vol. 75, no. 3, pp. 655-663, 2007.

[45] Y. Bashan, G. Holguin, and L. E. De-Bashan, "Azospirillumplant relationships: physiological, molecular, agricultural, and environmental advances (1997-2003)," Canadian Journal of Microbiology, vol. 50, no. 8, pp. 521-577, 2004.

[46] C. Wamberg, S. Christensen, I. Jakobsen, A. K. Müller, and S. J. Sørensen, "The mycorrhizal fungus (Glomus intraradices) affects microbial activity in the rhizosphere of pea plants (Pisum sativum)," Soil Biology and Biochemistry, vol. 35, no. 10, pp. 1349-1357, 2003.

[47] L. Lioussanne, F. Perreault, M. Jolicoeur, and M. St-Arnaud, "The bacterial community of tomato rhizosphere is modified by inoculation with arbuscular mycorrhizal fungi but unaffected by soil enrichment with mycorrhizal root exudates or inoculation with Phytophthora nicotianae," Soil Biology and Biochemistry, vol. 42, no. 3, pp. 473-483, 2010.

[48] E. A. Robleto, J. Borneman, and E. W. Triplett, "Effects of bacterial antibiotic production on rhizosphere microbial communities from a culture-independent perspective," Applied and 
Environmental Microbiology, vol. 64, no. 12, pp. 5020-5022, 1998.

[49] Y. Z. Zhang, E. T. Wang, M. Li et al., "Effects of rhizobial inoculation, cropping systems and growth stages on endophytic bacterial community of soybean roots," Plant and Soil, vol. 347, no. 1, pp. 147-161, 2011.

[50] P. Offre, B. Pivato, S. Siblot et al., "Identification of bacterial groups preferentially associated with mycorrhizal roots of Medicago truncatula," Applied and Environmental Microbiology, vol. 73, no. 3, pp. 913-921, 2007.

[51] Z. P. Xie, C. Staehelin, H. Vierheilig et al., "Rhizobial nodulation factors stimulate mycorrhizal colonization of nodulating and nonnodulating soybeans," Plant Physiology, vol. 108, no. 4, pp. 1519-1525, 1995.

[52] Y. Okon and C. A. Labandera-Gonzalez, "Agronomic applications of Azospirillum: an evaluation of 20 years worldwide field inoculation," Soil Biology and Biochemistry, vol. 26, no. 12, pp. 1591-1601, 1994.

[53] S. Dobbelaere, A. Croonenborghs, A. Thys et al., "Responses of agronomically important crops to inoculation with Azospirillum," Australian Journal of Plant Physiology, vol. 28, no. 9, pp. 871-879, 2001.

[54] M. Malhotra and S. Srivastava, "An ipdC gene knock-out of Azospirillum brasilense strain SM and its implications on indole-3-acetic acid biosynthesis and plant growth promotion," International Journal of General and Molecular Microbiology, vol. 93, no. 4, pp. 425-433, 2008.

[55] C. Jacoud, D. Faure, P. Wadoux, and R. Bally, "Development of a strain-specific probe to follow inoculated Azospirillum lipoferum CRT1 under field conditions and enhancement of maize root development by inoculation," FEMS Microbiology Ecology, vol. 27, no. 1, pp. 43-51, 1998.

[56] O. Steenhoudt and J. Vanderleyden, "Azospirillum, a freeliving nitrogen-fixing bacterium closely associated with grasses: genetic, biochemical and ecological aspects," FEMS Microbiology Reviews, vol. 24, no. 4, pp. 487-506, 2000.

[57] A. Schüßler, D. Schwarzott, and C. Walker, "A new fungal phylum, the Glomeromycota: phylogeny and evolution," Mycological Research, vol. 105, no. 12, pp. 1413-1421, 2001.

[58] S. E. Smith and D. J. Read, Mycorrhizal Symbiosis, Academic Press, London, UK, 3rd edition, 2008.

[59] V. Artursson, R. D. Finlay, and J. K. Jansson, "Interactions between arbuscular mycorrhizal fungi and bacteria and their potential for stimulating plant growth," Environmental Microbiology, vol. 8, no. 1, pp. 1-10, 2006.

[60] R. G. Linderman, "Mycorrhizal interactions with the rhizosphere microflora: the mycorrhizosphere effect," Phytopathology, vol. 78, pp. 366-371, 1988.

[61] T. R. Cavagnaro, L. E. Jackson, J. Six et al., "Arbuscular mycorrhizas, microbial communities, nutrient availability, and soil aggregates in organic tomato production," Plant and Soil, vol. 282, no. 1-2, pp. 209-225, 2006.

[62] A. Albertsen, S. Ravnskov, H. Green, D. F. Jensen, and J. Larsen, "Interactions between the external mycelium of the mycorrhizal fungus Glomus intraradices and other soil microorganisms as affected by organic matter," Soil Biology and Biochemistry, vol. 38, no. 5, pp. 1008-1014, 2006.

[63] P. A. Olsson, E. Bååth, I. Jakobsen, and B. Söderström, "Soil bacteria respond to presence of roots but not to mycelium of arbuscular mycorrhizal fungi," Soil Biology and Biochemistry, vol. 28, no. 4-5, pp. 463-470, 1996.
[64] P. Marschner and S. Timonen, "Timonen, Bacterial community composition and activity in rhizosphere of roots colonized by arbuscular mycorrhizal fungi," in Microbial Activity in the Rhizosphere, K. G. Mukerji, C. Manoharachary, and J. Singh, Eds., pp. 139-154, Springer, Berlin, Germany, 2006.

[65] G. Andrade, K. L. Mihara, R. G. Linderman, and G. J. Bethlenfalvay, "Bacteria from rhizosphere and hyphosphere soils of different arbuscular-mycorrhizal fungi," Plant and Soil, vol. 192, no. 1, pp. 71-79, 1997.

[66] J. M. Barea, "Mycorrhiza-bacteria interactions on plant growth promotion," in Plant Growth Promoting Rhizobacteria, A. Ogoshi, L. Kobayashi, Y. Homma, F. Kodama, N. Kondon, and S. Akino, Eds., pp. 150-158, OECD Press, Paris, France, 1997.

[67] J. M. Barea, R. Azcón, and C. Azcón-Aguilar, "Mycorrhizosphere interactions to improve plant fitness and soil quality," Antonie van Leeuwenhoek, International Journal of General and Molecular Microbiology, vol. 81, no. 1-4, pp. 343-351, 2002.

[68] E. Gamalero, M. G. Martinotti, A. Trotta, P. Lemanceau, and G. Berta, "Morphogenetic modifications induced by Pseudomonas fluorescens A6RI and Glomus mosseae BEG12 in the root system of tomato differ according to plant growth conditions," New Phytologist, vol. 155, no. 2, pp. 293-300, 2002.

[69] M. St-Arnaud and V. Vujanovic, "Effect of the arbuscular mycorrhizal symbiosis on plant diseases and pests," in Arbuscular Mycorrhizae in Crop Production, C. Hamel and C. Plenchette, Eds., pp. 67-122, Haworth's Food Products Press, New York, NY, USA, 2007.

[70] B. Li, S. Ravnskov, G. Xie, and J. Larsen, "Biocontrol of Pythium damping-off in cucumber by arbuscular mycorrhiza-associated bacteria from the genus Paenibacillus," BioControl, vol. 52, no. 6, pp. 863-875, 2007.

[71] F. A. Solís-Domínguez, A. Valentín-Vargas, J. Chorover, and R. M. Maier, "Effect of arbuscular mycorrhizal fungi on plant biomass and the rhizosphere microbial community structure of mesquite grown in acidic lead/zinc mine tailings," Science of the Total Environment, vol. 409, no. 6, pp. 1009-1016, 2011.

[72] M. Mar Vázquez, S. César, R. Azcón, and J. M. Barea, "Interactions between arbuscular mycorrhizal fungi and other microbial inoculants (Azospirillum, Pseudomonas, Trichoderma) and their effects on microbial population and enzyme activities in the rhizosphere of maize plants," Applied Soil Ecology, vol. 15, no. 3, pp. 261-272, 2000.

[73] M. Filion, M. St-Arnaud, and J. A. Fortin, "Direct interaction between the arbuscular mycorrhizal fungus Glomus intraradices and different rhizosphere microorganisms," New Phytologist, vol. 141, no. 3, pp. 525-533, 1999.

[74] A. Elsen, D. Gervacio, R. Swennen, and D. De Waele, "AMFinduced biocontrol against plant parasitic nematodes in Musa sp.: a systemic effect," Mycorrhiza, vol. 18, no. 5, pp. 251-256, 2008.

[75] M. R. Khan, N. Khan, and S. M. Khan, "Evaluation of agricultural materials as substrate for mass culture of fungal biocontrol agents of fusarial wilt and root knot nematode diseases," Annals of Applied Biology, vol. 22, pp. 50-51, 2001.

[76] B. R. Kerry, "Rhizosphere interactions and the exploitation of microbial agents for the biological control of plant-parasitic nematodes," Annual Review of Phytopathology, vol. 38, pp. 423441, 2000.

[77] M. R. Khan, Plant Nematodes-Methodology, Morphology, Systematics, Biology and Ecology, Science Publishers, Enfield, NH, USA, 2008. 
[78] K. K. Pal, K. V. B. R. Tilak, A. K. Saxena, R. Dey, and C. S. Singh, "Antifungal characteristics of a fluorescent Pseudomonas strain involved in the biological control of Rhizoctonia solani," Microbiological Research, vol. 155, no. 3, pp. 233-242, 2000.

[79] M. R. Khan, "Prospects of microbial control of root-knot nematodes infecting vegetable crops," in Biotechnology: Plant Health Management, N. Sharma and H. B. Singh, Eds., pp. 643-665, International Book Distributing Company, Lucknow, India, 2007.

[80] R. Singh, T. N. Parameswaran, E. V. S. P. Rao et al., "Effect of arbuscular mycorrhizal fungi and Pseudomonas fluorescens on root-rot and wilt, growth and yield of Coleus forskohlii," Biocontrol Science and Technology, vol. 19, no. 8, pp. 835-841, 2009.

[81] L. Zelles, "Fatty acid patterns of phospholipids and lipopolysaccharides in the characterisation of microbial communities in soil: a review," Biology and Fertility of Soils, vol. 29, no. 2, pp. 111-129, 1999.

[82] H. Yao, Z. He, M. J. Wilson, and C. D. Campbell, "Microbial biomass and community structure in a sequence of soils with increasing fertility and changing land use," Microbial Ecology, vol. 40, no. 3, pp. 223-237, 2000.

[83] W. F. Pfender, V. P. Fieland, L. M. Ganio, and R. J. Seidler, "Microbial community structure and activity in wheat straw after inoculation with biological control organisms," Applied Soil Ecology, vol. 3, no. 1, pp. 69-78, 1996.

[84] J. Heinonsalo, P. Frey-Klett, J. C. Pierrat, J. L. Churin, D. Vairelles, and J. Garbaye, "Fate, tree growth effect and potential impact on soil microbial communities of mycorrhizal and bacterial inoculation in a forest plantation," Soil Biology and Biochemistry, vol. 36, no. 2, pp. 211-216, 2004.

[85] P. Frey-Klett, J. C. Pierrat, and J. Garbaye, "Location and survival of mycorrhiza helper Pseudomonas fluorescens during establishment of ectomycorrhizal symbiosis between Laccaria bicolor and Douglas fir," Applied and Environmental Microbiology, vol. 63, no. 1, pp. 139-144, 1997.

[86] A. Natsch, C. Keel, N. Hebecker, E. Laasik, and G. Défago, "Impact of Pseudomonas fluorescens strain CHA0 and a derivative with improved biocontrol activity on the culturable resident bacterial community on cucumber roots," FEMS Microbiology Ecology, vol. 27, no. 4, pp. 365-380, 1998.

[87] K. Prévost, G. Couture, B. Shipley, R. Brzezinski, and C. Beaulieu, "Effect of chitosan and a biocontrol streptomycete on field and potato tuber bacterial communities," BioControl, vol. 51, no. 4, pp. 533-546, 2006.

[88] W. Vahjen, J. C. Munch, and C. C. Tebbe, "Carbon source utilization of soil extracted microorganisms as a tool to detect the effects of soil supplemented with genetically engineered and non-engineered Corynebacterium glutamicum and a recombinant peptide at the community level," FEMS Microbiology Ecology, vol. 18, no. 4, pp. 317-328, 1995.

[89] W. Janisiewicz, "Ecological diversity, niche overlap, and coexistence of antagonists used in developing mixtures for biocontrol of postharvest diseases of apples," Phytopathology, vol. 86, no. 5, pp. 473-479, 1996.

[90] S. Marimuthu, P. Subbian, V. Ramamoorthy, and R. Samiyappan, "Synergistic effect of combined application of Azospirillum and Pseudomonas fluorescens with inorganic fertilizers on root rot incidence and yield of cotton," Journal of Plant Diseases and Protection, vol. 109, no. 6, pp. 569-577, 2002.

[91] A. Probanza, J. A. Lucas García, M. Ruiz Palomino, B. Ramos, and F. J. Gutiérrez Mañero, "Pinus pinea L. seedling growth and bacterial rhizosphere structure after inoculation with PGPR Bacillus (B. licheniformis CECT 5106 and B. pumilus CECT 5105)," Applied Soil Ecology, vol. 20, no. 2, pp. 75-84, 2002. 

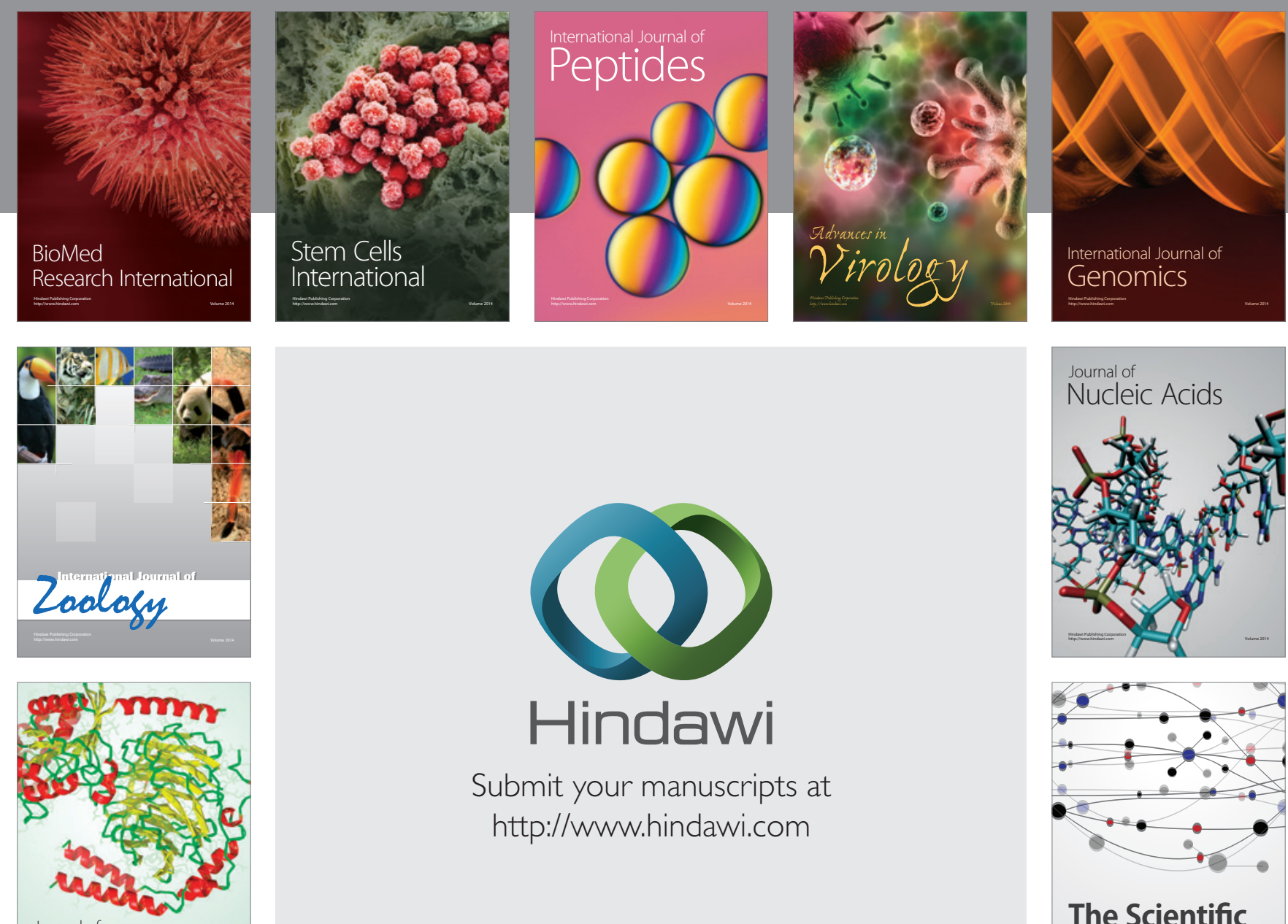

Submit your manuscripts at

http://www.hindawi.com

Journal of
Signal Transduction
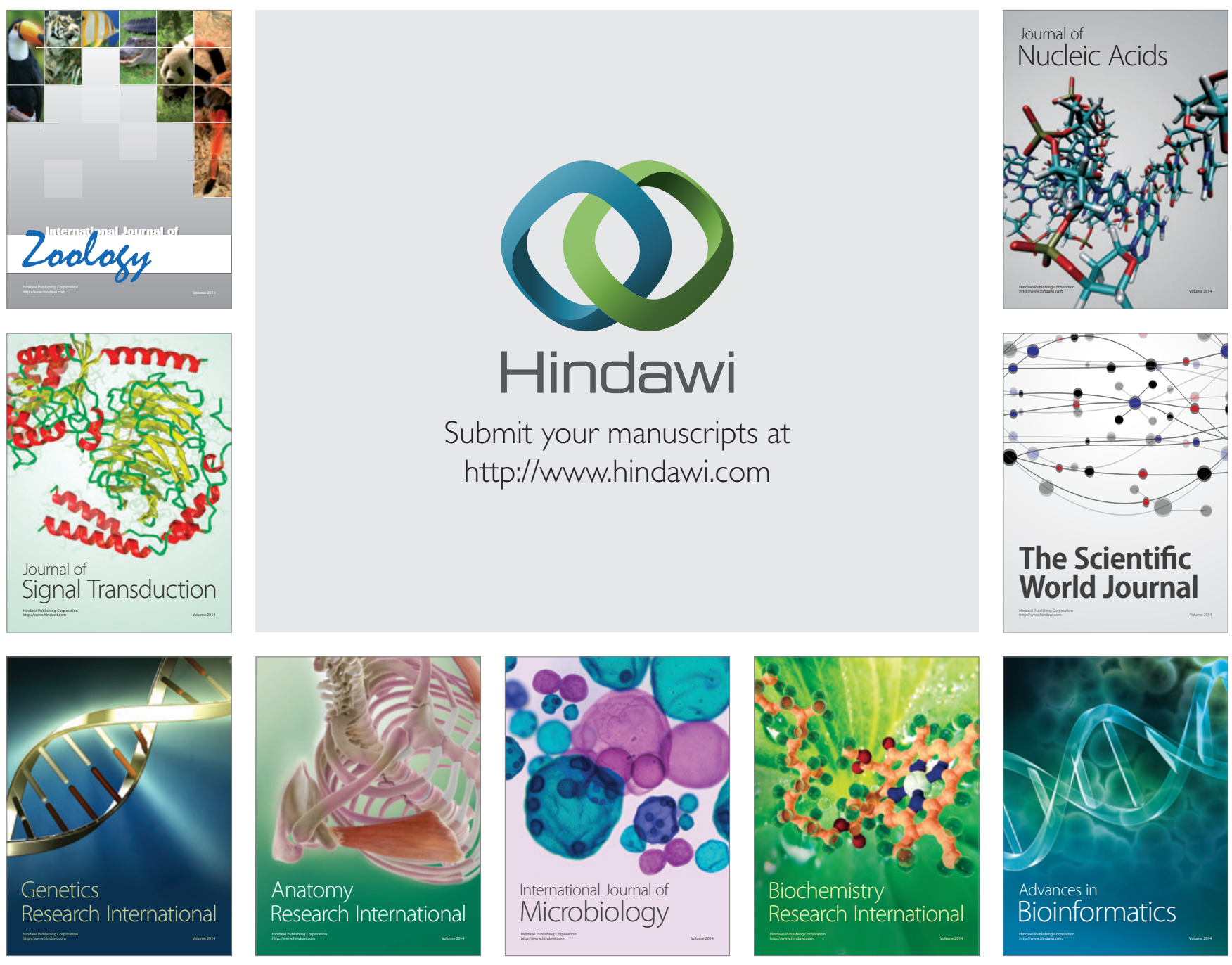

The Scientific World Journal
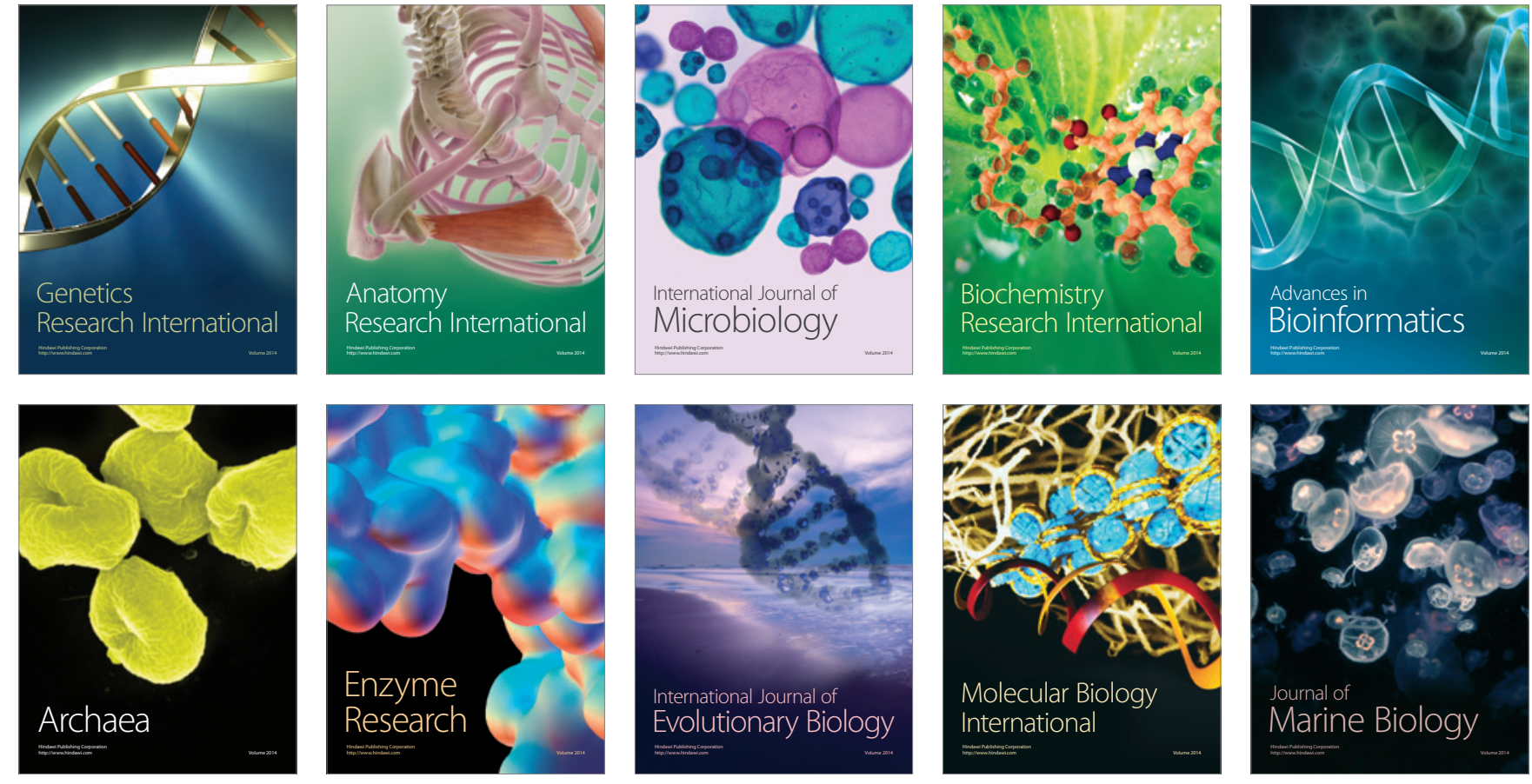